\title{
INTERPRETACIÓN GEOGRÁFICA DE LA EXCLUSIÓN SOCIO- ESPACIAL EN UNA CIUDAD INTERMEDIA DE COLOMBIA. Caso de estudio, borde urbano sur-oriental de Pereira.
}

\author{
INTERPRETAÇÃO GEOGRÁFICA DA EXCLUSÃO SÓCIO-ESPACIAL \\ EM UMA CIDADE MEIO DA COLÔMBIA. Estudo de caso da borda \\ urbana sudeste da cidade de Pereira.
}

\section{GEOGRAPHICAL INTERPRETATION OF SOCIAL EXCLUSION IN AN INTERMEDIATE COLOMBIAN CITY. Case south-east border area of Pereira.}

\author{
Jorge Andrés Rivera Pabón \\ Administrador del Medio Ambiente, Universidad Tecnológica de Pereira, UTP. \\ Magíster en Geografía con énfasis en Ordenamiento Territorial. Convenio UPTC-IGAC \\ Departamento de Historia y Geografía. Profesor Universidad de Caldas / Colombia \\ Calle Betania 10-12; 1 o (primero), 4o (cuarto) \\ Código postal: 08023 Barcelona, España. \\ jorgeandres.rivera@ucaldas.edu.co ; http://riverapabon.blogspot.com/
}

\section{Resumen}

El presente artículo exhibe una interpretación geográfica de los procesos de exclusión social ocurridos en las periferias urbanas de los municipios intermedios de Colombia; para tal fin se toma al municipio de Pereira como área de estudio, por ser un espacio de atracción y recepción de población "desterrada" (en particular, del Choco Biogeográfico). De esta forma, el análisis aborda una investigación estructural, dialéctica, escalar e histórica que profundiza en las raíces de la segregación espacial urbana; por esta razón, se incorporan las causas sociales, económicas, políticas, culturales y biofísicas determinantes en dicho fenómeno.

Palabras claves: Territorio, paisaje, desplazamiento, segregación socio-espacial.

\section{Resumo}

Este artigo apresenta uma interpretação geográfica dos processos de exclusão social ocorridos em periferias urbanas dos municípios intermediários da Colômbia; para este fim, Pereira é assumida como área de estudo, por ser um espaço de atração de população migratória forçada (em particular, da Choco biogeográfico). Assim, a análise aborda um inquérito, a pesquisa estrutural, dialética, histórica para entrar nas raízes da 
segregação espacial urbana, por esta razão, incorporando as causas sociais, econômicas, políticas, culturais, biofísicos determinantes e decisivas neste fenômeno.

Palavras-chave: Território, paisagem, deslocamento (população migratória forçada) e segregação espacial.

\begin{abstract}
The present article shows a geographical interpretation of social exclusion processes happened on outskirts of intermediate Colombia municipalities; for this end, Pereira Municipality is assumed as study area, for being an attraction space of forced migrant population (in particular, of the Biogeographical Choco Zone). By this mean, the analysis approaches a structural, dialectical, scale and historical academic research to go deeply into the roots of urban spacial segregation; for this reason, the decisive social, economic, political, cultural and biophysical causes of such phenomenon are incorporated.
\end{abstract}

Key words: Territory, landscape, forced migration, space segregation

\title{
Introducción
}

Con el ánimo de afrontar la comprensión holística y multideterminada de la relación existente entre el proceso de territorialización, la segregación o exclusión socio-espacial y la transformación del paisaje, se debe auscultar, en primer lugar, los fundamentos teóricos y metodológicos que permitan explicarlo desde la aproximación integral deseada. Para ello, se propone reconocer el espacio geográfico desde su base material (biofísica o natural) pero también como un espacio reformado y recreado permanentemente por el hombre en su diario devenir y relación con la naturaleza, es decir, un espacio "socialmente construido", o en palabras de Milton Santos, la "metamorfosis del espacio habitado".

En este orden de ideas, se plantean tres preguntas o núcleos problemáticos que guían el desarrollo y estructura de este artículo. El primero es, ¿Qué factores y causas han incidido en la dinámica de segregación socio-espacial en el borde sur-oriental de la ciudad de Pereira?; el segundo, ¿Cómo han influido y actuado los conflictos de carácter social suscitados en diversos ámbitos y escalas geográficas (nacional, regional, departamental), en la configuración de Asentamientos Humanos en el borde o periferia urbana analizada en Pereira durante su historia reciente (desde la década de los ochenta)?; y el tercero, ¿Cuáles han sido las consecuencias socio-naturales 
(ambientales) de la conformación permanente y acelerada de espacios marginales y segregados en el área de estudio?

Para dar respuesta a estas preguntas, se presentan como principales puntos o ítems a desarrollar, las reflexiones sobre los aspectos sociales del contexto regional y local. De esta manera, a partir del reconocimiento de las características poblacionales, del poblamiento y ocupación del territorio, como de los factores culturales, políticos y económicos (actividades productivas, promotores de la vivienda, etc.) se podrá evaluar y detectar los desequilibrios o problemas resultantes del proceso de territorialización, entre ellos la lucha por la propiedad de la tierra, la vivienda y la consolidación del hábitat barrial caracterizado por la segregación socio-espacial, sus conflictos sociales y ambientales coligados. Así, el análisis territorial permitirá explicar la relación existente entre la problemática actual de la utilización del espacio geográfico regional y sus repercusiones locales en las dinámicas de exclusión.

Paralelamente, se contempla la inserción de los aspectos biofísicos en el análisis territorial en razón a que no se puede entender un paisaje transformado y la configuración de asentamientos humanos sin tener en cuenta la interrelación e imbricación con la estructura natural. Esta interpretación deja entrever, la necesidad de una lectura alternativa de la relación sociedad-naturaleza, por cuanto indica que ella no debe entenderse como una interacción entre dos entidades independientes, ya que la sociedad misma tiene condiciones naturales propias de su misma modalidad del ser, que operan en su interior como determinaciones de existencia (CORAGGIO, p. 20). Esta acepción abre el camino para abordar las variables y estructuras que explican la categoría espacio geográfico, en tanto propuesta conceptual formalizada a partir de su entendimiento como realidad natural, social e histórica. De la misma forma, la comprensión de la problemática ambiental transita por incluir las categorías constitutivas de los factores, elementos y relaciones que intervienen en su ocurrencia, a través de la construcción social del espacio geográfico y en función de su transformación histórica ${ }^{1}$. Finalmente, se expresan los resultados logrados y las

\footnotetext{
${ }^{1}$ En la sociedad se conciben una serie de problemáticas originadas en la unión y relación dialéctica entre las formaciones sociales y el mundo natural. Los seres humanos como una especie biológica particular en la lucha por la supervivencia transforman el ambiente. Como parte de esta lucha, entran en una relación social, en la cual se le da al espacio una forma, una función, una significación social. El espacio entonces, es una expresión concreta de cada ensamblaje histórico en el que la sociedad está involucrada. Citado con base en: PEET, Richard. Modern Geographical Thought. Blackwell Publishers. Oxford, 1998., p. 125.
} 
conclusiones del análisis de la territorialización de asentamientos humanos en el borde sur-oriental de Pereira, caracterizado por ser un área marginada y de exclusión social histórica. Así, se hace énfasis en algunos barrios objeto de la indagación, como son La Dulcera, La Platanera, Hamburgo, El Poblado I y El Dorado.

\section{Objetivos}

- Exponer un marco teórico y metodológico de análisis territorial crítico e interpretativo de la segregación socio-espacial y los conflictos ambientales, con base en un enfoque geográfico e interdisciplinario, aplicado en la zona de estudio.

- Realizar un análisis territorial en el borde o periferia urbana sur-oriental de Pereira (barrios La Dulcera, La Platanera, El Poblado I, Hamburgo y El Dorado), con el propósito de identificar las causas del fenómeno de segregación y exclusión socio-espacial asociado al proceso reciente de configuración de asentamientos humanos, desde la década de 1980.

- Determinar los factores, elementos y relaciones estructurales involucrados en la segregación socio-espacial e identificar algunos conflictos ambientales acaecidos en el marco de la relación comunidad-medio o sociedad-naturaleza, durante el proceso de urbanización sucedido en las tres últimas décadas.

\section{Referentes teóricos y conceptuales}

\subsection{Territorio y territorialidad}

Considerando la incorporación de los componentes políticos y culturales en el estudio de la segregación o exclusión socio-espacial se dirige la atención hacia la noción de territorio, particularmente desde un enfoque geográfico y de análisis interdisciplinario en las Ciencias Humanas. La palabra Territorio se deriva de las raíces latinas terra y torium, que conjuntamente significan la tierra que pertenece a alguien (LOBATO, 1990, p. 20). El territorio, es por tanto, un concepto relacional que insinúa un conjunto de vínculos de dominio, de poder, de pertenencia o de apropiación entre una porción o la totalidad del espacio geográfico y un determinado sujeto individual o colectivo. De ahí que cuando se designa un territorio siempre se está asumiendo, aún de 
manera implícita, la existencia de un espacio geográfico y de un sujeto que ejerce sobre él cierto dominio, una relación de poder, una calidad de poder, una calidad de poseedor o una facultad de apropiación. La relación de pertinencia no se refiere sólo a vínculos de propiedad sino también a aquellos lazos subjetivos de identidad y afecto existentes entre el sujeto y su territorio. Ese sujeto individual o colectivo contiene generalmente una porción de poder suficiente para incidir en la transformación de ese territorio. El territorio es, pues, el espacio geográfico revestido de las dimensiones política, identitaria y afectiva, o de todas ellas.

Aunque cada territorio se define en relación con un determinado sujeto individual o colectivo que ejerce un dominio hegemónico sobre cierta porción del espacio geográfico, ese dominio raras veces es absoluto. Con respecto a un mismo territorio pueden coexistir muchos sujetos que, no obstante ser subordinados al aspecto económico, ejercen diferentes grados de dominio territorial, con frecuencia selectivo y jerárquico. De allí se deriva la distinción entre territorio y territorialidad.

Se entiende por territorialidad el grado de dominio que tiene cierto sujeto (s) en un espacio geográfico, así como el conjunto de prácticas y sus expresiones materiales y simbólicas, capaces de garantizar la apropiación y permanencia de un territorio dado bajo algún agente (s). Los sujetos que ejercen territorialidades pueden ser individuos, grupos sociales, grupos étnicos, etc. Las territorialidades se crean, recrean y transforman históricamente en procesos complejos de territorialización o desterritorialización, impulsados a través de mecanismos consensuados (comunidades residentes en áreas planificadas) o conflictivos (ocupación de áreas por procesos de invasión de comunidades desplazadas), de carácter gradual o abrupto. A partir de esta aproximación conceptual se muestra que la exclusión socio-espacial se inscribe en la lógica de la migración constituida por población desplazada y desterrada, la cual adquiere gran importancia, en tanto reviste la particularidad de manifestar la influencia y causalidad entre los procesos de migración forzosa, re-poblamiento y territorialización en el ámbito urbano. Desde esta perspectiva, es imperativo asumir la propuesta conceptual y de análisis de la geografía de la población, al estudiar las características socio-demográficas de los procesos migratorios y de emplazamiento o distribución espacial de la población. 


\section{El movimiento migratorio de la población}

Las migraciones constituyen junto con la natalidad y mortalidad, las variables fundamentales para determinar los cambios en la estructura demográfica de los entes territoriales, y de la redistribución espacial de la población. Además, existe una significativa identificación en diversos estudios de población en aceptar, que las migraciones y su impacto en la distribución territorial de la población están altamente correlacionados con las estrategias globales de desarrollo. En forma general "La migración entendida como una forma de movilidad espacial entre dos unidades geográficas involucrando un cambio de residencia, ha sido estudiada bajo diferentes causas determinantes, agrupados como factores geográficos, socio-económicos y demográficos" ${ }^{2}$.

En Colombia han operado muchos de estos factores generadores de flujos migratorios hacia las ciudades, conllevando a un proceso de ocupación espacial de los centros urbanos sin mediar planificación y políticas adecuadas para intervenir este proceso. Las tendencias migratorias en Colombia, generalmente están caracterizadas por el éxodo rural a la ciudad, esta migración rural-urbana ha afectado a partir de la segunda mitad del Siglo XX, el espacio urbano que afronta una recepción constante de población, constituyendo además la otra faceta del despoblamiento del campo. De igual manera, la comprensión y explicación de los procesos de ocupación espacial y poblamiento urbano en Colombia, aborda el fenómeno del desplazamiento, por ser un componente fundamental en la configuración de asentamientos humanos en algunas áreas no adecuadas para este propósito, especialmente en los últimos años cuando la situación de conflicto interno que vive el país, ha conducido a un enorme flujo poblacional de llegada de población desplazada a las principales ciudades, situación nacional que se ha hecho evidente en Pereira. Este hecho poblacional fue tipificado por la Ley 387 de 1997, quien considera como desplazado a:

\footnotetext{
"Toda persona que se ha visto obligada a migrar dentro del territorio nacional abandonando su localidad de residencia o sus actividades económicas habituales porque su vida, su integridad física, su seguridad o libertad personal han sido vulneradas o se encuentran directamente amenazados con ocasión de cualquiera de las siguientes situaciones de conflicto armado interno, disturbios o tensiones interiores, violencia generalizada, violaciones masivas de los derechos humanos, infracciones al derecho internacional humanitario u otras
}

\footnotetext{
${ }^{2} \mathrm{NACIONES} \mathrm{UNIDAS.} \mathrm{The} \mathrm{determinants} \mathrm{and} \mathrm{consecuences} \mathrm{of} \mathrm{population} \mathrm{trends.} \mathrm{Vol.} \mathrm{1,} \mathrm{Capítulo} \mathrm{VI,}$
} 1993. 
situaciones emanadas de las anteriores que pueden alterar o alteren drásticamente el orden público".

El desplazamiento poblacional debe ser analizado con un enfoque multidimensional, multitemporal y multiescalar. Este hecho se ha manifestado en diferentes periodos de la historia nacional, asociado a factores de naturaleza política, económica y social. El análisis en este sentido debe vincularse históricamente a los factores detonantes de la problemática existente en los territorios causantes de los despoblamientos y reubicaciones poblacionales individuales o colectivas. De otra parte, la movilidad poblacional expresa o atiende diferentes escalas o ámbitos espaciales de expulsión y atracción, en tanto que los flujos o direcciones rebasan la escala local. Los nuevos emplazamientos poblacionales de la población desplazada suelen producirse en su región o en otras regiones, configurando relaciones e interdependencias entre diferentes territorios del espacio nacional.

\subsection{Espacio Geográfico y segregación socio-espacial}

La cuestión de los cambios producidos en el espacio geográfico por la configuración de asentamientos humanos caracterizados por procesos de exclusión o segregación socio-espacial ha sido muy estudiada en los últimos tiempos por las ciencias sociales y la geografía urbana en particular. La literatura que trata de la reestructuración del espacio urbano, de los nuevos espacios de asentamiento, es significativa en la geografía, en la sociología y en el urbanismo. Hay importantes líneas de investigación y autores con distintas orientaciones teóricas y metodológicas volviendo sus intereses sobre el tema ${ }^{3}$.

De acuerdo a lo planteado por Rodrigues (1999, p. 3), desde la geografía autores como David Harvey (1989), Edward Soja(1989), Mark Gottdiener (1985), como también Joan Eugeni Sánchez (1979) en el ámbito español, han estudiado desde diferentes punto de vista aspectos tales como, los fenómenos de desconcentración metropolitana y la dispersión urbana, al igual que la incorporación de la categoría del

\footnotetext{
${ }^{3}$ Se presentan diferentes visiones, concepciones teóricas y formas de explicar los cambios sucedidos en el espacio geográfico, a partir de enfoques tan diversos como el estructuralismo, la estructuración y el postmodernismo. Citado con base en: Rodrigues S. Paulo. Contradicciones de la producción de la
} 
poder en su relación con el espacio, o en otras palabras, cómo las necesidades de la propia estructura de poder dominante transforman el espacio geográfico en un espacio social del poder. En esta reflexión se ha dado preferencia a los análisis globales de la sociedad en los marcos de la transición hacia un nuevo "modo de regulación" de las relaciones de producción capitalistas (Harvey), a la "geografía histórica de la reestructuración regional" (Soja), a la "organización regional de la vida cotidiana" (Gottdiener) y a "la relación entre la organización política de la sociedad y el espacio geográfico" (Sánchez).

Así mismo, Rodrigues (1999, p. 3) plantea que al tener como matriz teórica la misma idea de Henri Lefebvre del "espacio como producto de la reproducción de las relaciones de producción", se busca en sus análisis los condicionantes de un proceso evidente empíricamente: el actual cambio en la forma y en la organización de los espacios urbanos. Las ciudades crecen absorbiendo antiguos espacios rurales, alterando sus condiciones ambientales, construyendo "nuevos paisajes" urbanos. El espacio urbano se torna más diverso tanto en los flujos como en su paisaje, especialmente en las zonas o franjas que se van integrando a él (interfases urbano-rurales), donde los nuevos procesos son más dinámicos, debido a las condiciones sociales, económicas, culturales y políticas de los grupos sociales que construyen estos nuevos espacios urbanos de "borde o periferias".

Los nuevos pobladores son introducidos a los procesos de producción únicamente en sectores económicos que permiten la flexibilización del trabajo, o a través de actividades informales de mínima remuneración. Simultáneamente, esta "nueva población urbana" genera un proceso de ocupación espacial, que de una u otra manera presenta una relación directa o indirecta con diversos actores económicos y políticos. Así es necesario introducir también al análisis territorial, fenómenos como la producción inmobiliaria y las articulaciones entre promotores, constructores,

vivienda en la ciudad de rio grande, Brasil. En: Revista electrónica de geografía y ciencias sociales Scripta Nova. $\mathrm{N}_{0} 45$ (3). 1999. p. 3,4.

${ }^{4}$ El borde es, esencialmente, un ecotono, la franja de transición entre dos ecosistemas o dos áreas estructural y funcionalmente distintas (páramo-bosque, sabana-selva, rural-urbano, etc.). El borde, como estructura física y social del territorio, puede coincidir o no con los límites y perímetros establecidos por las normas y, por supuesto, su extensión es superior a la de una línea. El borde urbano abarca un área donde el entorno regional tiene influencia sobre la estructura y función urbanas más aquella donde, recíprocamente, éstas tienen efectos directos sobre las estructuras territoriales vecinas. Citado por: CAMARGO Ponce de León, Germán. La producción física y social de ciudad en sus bordes. En: Memorias I Congreso Nacional de Hábitat y Medio Ambiente. UTP. 2005.p.1. 
terratenientes de las ciudades y su influencia sobre el aparato de Estado (sobre todo en su esfera local). En definitiva, este tipo de premisas se incorporan y examinan en el caso del municipio de Pereira. Se intenta, de esta forma entender y explicar los procesos que rigen la producción del espacio - un espacio fuertemente marcado por la intervención política y por los impactos asociados a la actividad económica.

\subsection{Paisaje.}

Cuando se intenta examinar e interpretar el origen, dinámica y factores que determinan la segregación socio-espacial, al igual que sus consecuencias, un corolario inevitable es la producción de conflictos ambientales. Por esta razón, es necesario reconocer que un criterio medular en la exégesis de esta problemática es el estudio del medio físico-biótico, lugar en el cual se producen y "expresan" dichos conflictos. Es así como hay que asumir un enfoque basado en una concepción integral de la relación sociedad-naturaleza; fundamentada en el hecho de que no existe oposición real en esta dupla de conceptos, sino que, por el contrario, existe una plena identidad en ellos. Por esto, los procesos ecológicos no desaparecen al interior de una formación social, ni tampoco es posible encontrar sociedades a-espaciales. De manera similar, las categorías espacio y tiempo no deben separarse en ningún proceso de conocimiento donde se pretenda comprender la segregación socio-espacial y su par dialéctico, los conflictos ambientales. La trascendencia de los hechos se plasma en el espacio y permanece como formas, garantizando así una espacialización en el tiempo. De esta manera, la comprensión de los conflictos ambientales se da a partir de la lectura del libro en que se escriben, el paisaje.

Con el objeto de abordar esta problemática desde la complejidad que la identifica, el concepto de Paisaje aquí enunciado formula y sintetiza dos acepciones, dos miradas teóricas integradas. La primera, comprende al paisaje como decantaciones históricas de la existencia humana en el espacio geográfico (geo-historia); el segundo como expresión y articulación sistémica de los elementos biofísicos y antrópicos (ecología del paisaje).

El paisaje, desde una perspectiva geo-histórica manifiesta una estrecha relación diacrónica en los procesos espacio-temporales que estructura y proyecta una sociedad, 
integrada con y en la naturaleza, convirtiendo el territorio no en un actor mudo, sino en testimonio. Precisamente, como lo expresa Molano (1991, p. 10) haciendo referencia de Lefevbre (1975) "nos han acostumbrado a creer y pensar que el pasado está muerto y que nada de lo pasado puede ser presente”: Pero el espacio social es una forma durable que integra pasado y presente, y además de coyuntura histórica es memoria de la sociedad. Las formas espaciales no son vacías, ni fósiles, son formas-contenido con plena posibilidad de participar en la dialéctica global de la sociedad. En este orden de ideas, los conflictos ambientales son resultado y se producen en la acción permanente que toda sociedad ejerce sobre el potencial físico biótico. Al producir la vida y reproducir la sociedad se está creando simultáneamente procesos extractivostransformadores, propios de la acción antrópica que son la llave indiscutible a la configuración de conflictos ambientales (degradación y transformación ambiental como consecuencia de la actividad productiva y de la vida de la sociedad y del hombre en su habitar).

De otro lado, y con base en el estudio de la relación sociedad-naturaleza, el

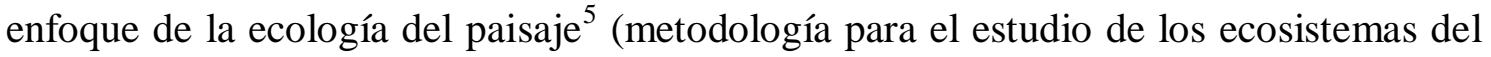
mundo con una perspectiva geográfica), caracteriza el paisaje a partir de una aproximación integral y no de la sumatoria (o superposición) de sus atributos analizados previamente en forma individual. Dicho enfoque se fundamenta en la fisiografía, disciplina que estudia, describe y clasifica sistemáticamente las formas del terreno, considerando para ello aspectos de geomorfología, geología e hidrogeología; también la incidencia de climas pasados y presente y ciertos aspectos bióticos (incluida la acción antrópica), en la medida en que su interacción en el tiempo hubiese impreso en los suelos unas características claramente definidas. La clasificación fisiográfica del terreno permite a la vez jerarquizar una zona cualquiera, de lo general a lo particular, con el ánimo que puedan utilizarse a distintas escalas y con diferente nivel de detalle. 


\section{CATELIÊ GEOGRÁFICO ISSN: 1982-1956

Gráfico l. Propuesta Teórica-Metodológica. (Geografia de Sintesis - Métodos mixtos)

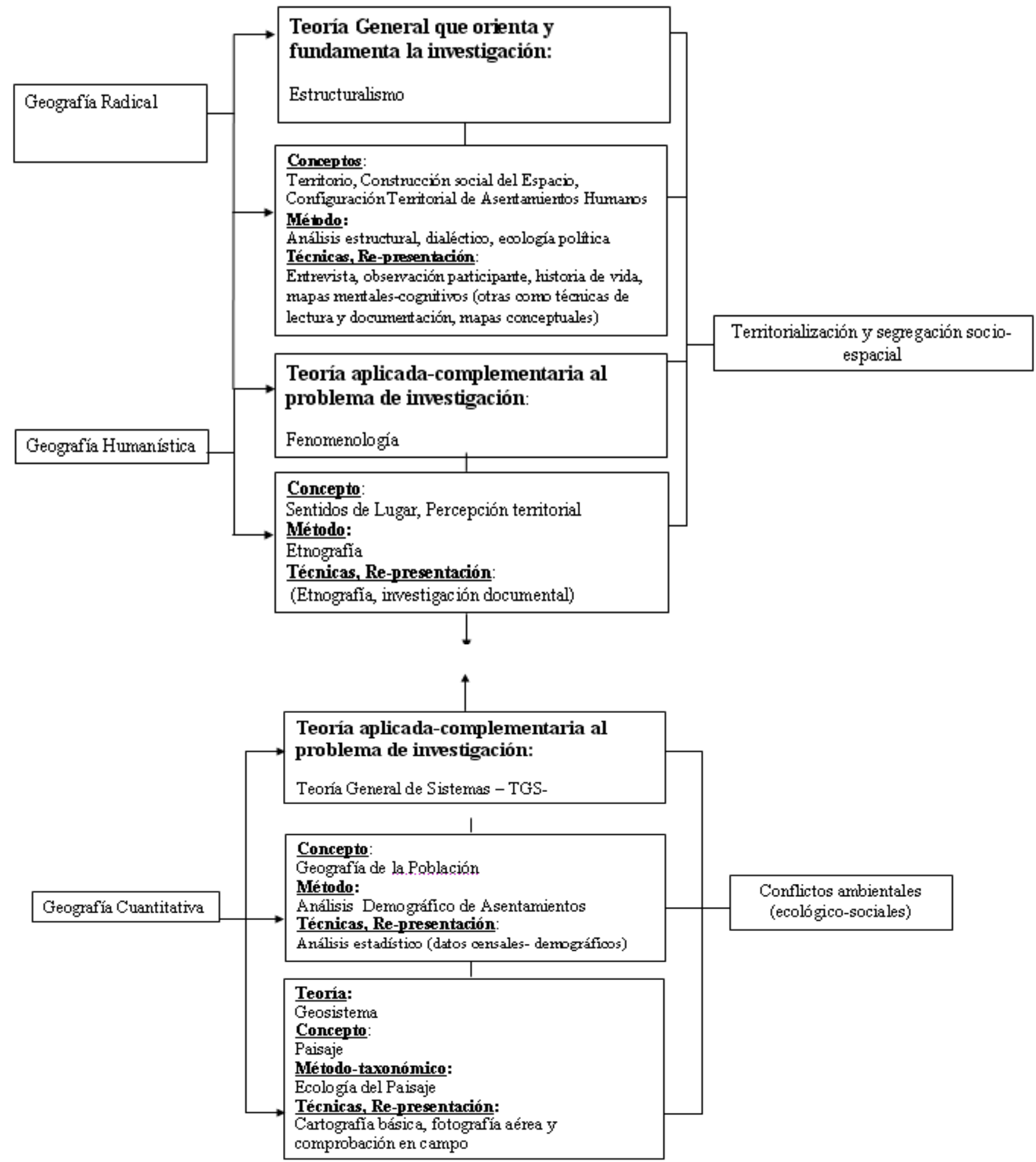

Fuente: Jorge Andrés Rivera Pabón

\footnotetext{
${ }^{5}$ Este enfoque es expuesto y definido con base en: VILLOTA, Hugo. Análisis de los atributos del paisaje en la zonificación ecológica. IGAC- CIAF. 1999.
} 


\section{Metodología}

Ante la complejidad del problema examinado, es decir, la correspondencia entre la territorialización de Asentamientos Humanos en zonas de borde o periferia urbana, los cuales evidencian segregación socio-espacial y conflictos ambientales, es pertinente emprender la investigación multi-método o métodos híbridos (Véase gráfico 1), siendo consecuentes con el propósito de efectuar un análisis integral y holístico (socionatural). Este enfoque metodológico emplea como eje articulador la síntesis interdisciplinaria entre la geografía humana y física ${ }^{6}$, y como ramas de extensión explicativas, aquellas disciplinas (antropología, sociología, economía, ecología del paisaje, urbana, política, etc.) que se internan en la consecución amplia, profunda e interpretativa de los procesos y relaciones que han venido formalizando la segregación y exclusión social y los problemas ambientales en espacios de interfase urbanorural.

\section{Principales cuestionamientos: "territorialidades en pugna"}

\subsection{Contexto Regional: Al encuentro de una mirada multiescalar,} multitemporal y multifactorial de la segregación socio-espacial.

Migraciones y Desplazamiento Forzoso: El departamento de Risaralda tiene el doble comportamiento de receptor y expulsor de población. Como expulsor, es particularmente sensible a la situación que se presenta sobre el área que corresponde al Choco biogeográfico donde se asientan los municipios de Mistrató y Pueblo Rico; sobre el Piedemonte del Parque Natural Tatamá donde se encuentran municipios como La Celia y Santuario, y en los municipios de Quinchía, Guática y Belén de Umbría donde se detecta permanentemente presencia de conflicto armado.

\footnotetext{
${ }^{6}$ Autores como Ley y Derycke esbozan como tema de interés para la geografía urbana, el estudio de la espacialidad de fenómenos como la marginación y segregación socio-espacial y su relación con el deterioro ambiental. De igual forma, José Estébañez, analiza el panorama actual de los estudios sobre el medio ambiente y su conexión con diferentes tradiciones conceptuales y metodológicas de la geografía humana; específicamente, postula un nuevo enfoque atento a los sentidos de lugar y diseña algunas líneas metodológicas para su aplicación práctica. Citado por: GARCIA, Ballesteros, Aurora. Geografía Urbana-1. 1995.
} 
Tabla 1. Risaralda. Municipios con presencia de Conflicto Armado ${ }^{7}$.

\begin{tabular}{|c|l|}
\hline Año & \multicolumn{1}{c|}{ Risaralda } \\
\hline 1999 & Mistrató, Pueblo Rico \\
\hline 2000 & Pueblo Rico, Quinchía, Guática, Mistrató \\
\hline 2001 & Belén de Umbría, Pueblo Rico, Guática, Quinchía, Mistrató \\
\hline $2002^{*}$ & $\begin{array}{l}\text { Pueblo Rico, Apía, Mistrató, Guática, Quinchía, Belén de } \\
\text { Umbría, Santuario }\end{array}$ \\
\hline
\end{tabular}

Fuente: Periódicos La Patria, Diario del Otún, La Tarde, El Tiempo.

La zona de destierro poblacional del Choco Biogeográfico, se caracteriza por unas condiciones ambientales propias de la zona selvática. En esta área se asienta una importante población afro-risaraldense, específicamente, en el Corregimiento de Santa Cecilia, municipio de Pueblo Rico. El territorio ocupado por esta población se identifica por ser un área de influencia y asiento permanente de actores armados (FARC, ELN, EPL, AUC) para quienes la zona tiene una condición estratégica al facilitar el paso entre el noroccidente y el suroccidente de Colombia.

De igual manera, se asienta sobre la zona del Choco Biogeográfico y los municipios de Quinchía, Guática y Marsella la comunidad indígena Emberá Chamí. Según estimativos del CRIR, la población de esta etnia se acerca a los 18 mil habitantes repartidos entre los diferentes resguardos y cabildos indígenas. Esta población ha recibido fuertes presiones por parte de los actores del conflicto armado, entre grupos guerrilleros y las Autodefensas Unidas de Colombia, en las zonas donde ellos se asientan. Esto se percibe principalmente en los municipios de Mistrató, Pueblo Rico y Quinchía, lugares que históricamente han sido de alta influencia guerrillera (presencia de ELN, EPL, FARC) y actualmente de los grupos de Autodefensa. De esta forma, el número de indígenas en condición de desplazamiento es creciente; convirtiendo a Pereira en lugar de recepción ${ }^{8}$.

\footnotetext{
7 Se asume la información del conflicto cuando se reporta enfrentamiento armado o presencia de grupos armados *datos a Marzo 2002 y corresponden en su mayoría a información sobre presencia de grupos armados (FARC, ELN, EPL, AUC entre otros).

${ }^{8}$ La población indígena desplazada durante el año de 2002 y acumulado hasta Enero 31 del 2003, asentada en el departamento de Risaralda fue de 107 familias y 496 personas, siendo el $3.87 \%$ del total de la población que por desplazamiento forzado se ubicó en el departamento. Igualmente, en la ciudad de Pereira se concentra el mayor número de familias desplazadas que al 31 de Enero de 2003, alcanzó las 1843 familias registradas y que representa un $67.4 \%$ del total de la población registrada y asentada en el departamento de Risaralda. Citado por: RED DE SOLIDARIDAD SOCIAL-UNIDAD TERRITORIAL RISARALDA. El desplazamiento en el departamento de Risaralda. 2003. p. 3, 4.
} 
De otra parte, es menester enunciar que la ubicación de los territorios indígenas y afro-colombianos en el departamento, coincide con el interés estatal por desarrollar grandes proyectos de infraestructura (vías de acceso al planeado puerto de Tribuga), y con el proceso de fortalecimiento de las Autodefensas.

Durante los últimos diez años ha crecido cada vez más la guerra en el territorio de estas comunidades, ligada a las territorialidades en pugna, es decir por el control de esta zona del departamento, importante por su gran biodiversidad y la proyección de macroproyectos de infraestructura y de negociación económica de servicios ambientales.

Tabla 2. Eje Cafetero. Familias y personas desplazadas. 1995-2001

\begin{tabular}{|c|c|c|c|c|}
\hline \multirow{2}{*}{ DEPARTAMENTO } & \multicolumn{2}{|c|}{ FAMILIAS } & \multicolumn{2}{c|}{ PERSONAS } \\
\cline { 2 - 5 } & Expulsadas & Recibidas & Expulsadas & Recibidas \\
\hline Caldas & 188 & 138 & 1.122 & 737 \\
\hline Quindío & 29 & 198 & 190 & 1.245 \\
\hline Risaralda & 344 & 879 & 2.006 & 5.193 \\
\hline Norte del Tolima & 243 & 651 & 1.539 & 3.888 \\
\hline Norte del Valle & 1.310 & 1.132 & 7.668 & 6.823 \\
\hline Total & 2.114 & 2.998 & 12.525 & 17.886 \\
\hline
\end{tabular}

Fuente: Red de Solidaridad Social. Sistema Único de Registro de Población Desplazada (SUR). 2001

Como lo muestra la tabla 2, el mayor porcentaje de familias expulsadas en la región conocida como eje cafetero lo presenta el Norte del Valle del Cauca con un $62 \%$, seguido con una gran diferencia por los departamentos de Risaralda con un $16 \%$, Tolima (municipios del noroccidente del departamento) con 11\%, Caldas que presenta un 9\% y Quindío con apenas el 1\%. Este proceso de desplazamiento interno de la población en la región es causado por factores como la disputa del control de la tierra y las persecuciones por motivos ideológicos o políticos. De esta forma, la violencia ejercida por grupos armados contra sectores de la población, está vinculada al interés por mantener el control territorial y la posesión de tierras en pocas manos. Este fenómeno de larga duración, se ha venido consolidando y recrudeciendo nuevamente a partir de la década de los 80, especialmente, porque los actores del conflicto armado han hecho de la población civil un objetivo militar; por esta razón ante los homicidios en masa, las desapariciones y amenazas de muerte, cientos de pobladores han tenido que salir masiva, familiar o individualmente de sus lugares de residencia y trabajo hacia los 
cascos urbanos de los municipios más cercanos, en esta lógica se configura la segregación socio-espacial del borde urbano sur-oriental de Pereira.

\subsection{Contexto Local.}

Para Pereira es pertinente explicar que la alta inmigración durante los últimos 40 años responde a diferentes causalidades. En un primer momento, el auge de la actividad cafetera y el sector de servicios, generó una ola migratoria correlacionada con estas actividades. Al respecto es importante señalar la incidencia de la demanda de fuerza de trabajo en la economía cafetera, actividad que fue desarrollada en Pereira especialmente en fincas muy cercanas al área urbana de la ciudad (zonas que hoy son urbanas, tal es el caso de la hacienda Naranjito, Samaria, etc) ${ }^{9}$. Esta aseveración se ve fundamentada en el comportamiento inmigratorio entre 1951-1993, que evidencia la constitución de "un área de alta atracción poblacional", especialmente en Dosquebradas y Pereira, ciudades que representan un saldo migratorio positivo por encima del promedio nacional. El período intercensal 1973-85, expuesto en la tabla 3 demuestra esta característica.

Tabla 3. Pereira-Dosquebradas. Saldo neto migratorio. 1973-1985

\begin{tabular}{|l|c|}
\hline Municipios & $\mathbf{1 9 7 3 - 1 9 8 5}$ \\
\hline Pereira & 17.968 \\
\hline Dosquebradas & 50.380 \\
\hline
\end{tabular}

Fuente: Censos DANE. Censos de Población y Vivienda.

Estas cifras reiteran la consolidación de un primer momento inmigratorio coligado a factores económicos, pero especialmente a la bonanza cafetera (década del 70 y primeros años de los 80), y su avance como un proceso de desarrollo capitalista agrario que potenció el municipio, generando el saldo migratorio de 17968 personas entre $1973-1985^{10}$. No

\footnotetext{
${ }^{9}$ Esta característica es evidenciada por Oscar Arango en: "Pereira, años 80" al explicar como el periodo intercensal 64-73 registro un crecimiento de -2, debido a la no actualización del DANE, del casco Urbano, el cual mediante decreto municipal había incluido varias veredas a éste, es decir que ya se constituían como Barrios, y el DANE no advirtió esa característica de incorporación de áreas. Citado con base en: ARANGO Oscar. Pereira Años 80. Funderalda, 1989. p. 14

${ }^{10}$ En general la inmigración al Área Metropolitana Centro-Occidente ha obedecido a un modelo de los flujos migratorios, en el cual la atracción de población a los nodos o polos de desarrollo, son concordantes con los flujos del capital en determinados sectores productivos (cafetero, manufacturero, industrial y
} 
obstante, y en especial a partir de 1985, el desarrollo nacional y regional se vio profundamente afectado por los cambios en los términos de negociación internacional del café, fenómeno agravado con posterioridad a 1989, año del rompimiento del Pacto Cafetero, lo que generó sucesivas crisis cafeteras y el aumento de la línea de pobreza rural y urbana y de $\mathrm{NBI}^{11}$.

Este proceso negativo de la economía regional se agudizó con la adopción del modelo de desarrollo neoliberal exigido por el nuevo orden internacional, el cual estaba direccionado a nivel mundial por organismos multilaterales como el Banco Mundial, el Fondo Monetario Internacional y a nivel continental, monitoreado por el Banco Interamericano de Desarrollo, etc. Este fenómeno manifiesta el impacto que ha causado la globalización en la economía local y regional. Especialmente, en el departamento de Risaralda se produjo un gran impacto en el plano económico; ya que su actividad principal y eje de desarrollo (el café), fue duramente golpeado por las leyes del comercio internacional y por la competencia de nuevos países productores como Vietnam, que han venido desarrollando su producción a costos muy bajos. Además, otros sectores importantes de la economía departamental, como son la industria manufacturera de muebles, textiles y confecciones empezaron a decaer vertiginosamente, debido entre otras cosas, a los requisitos de bajos costos laborales para ser "competitivos", (flexibilización del trabajo, etc.).

\section{Resultados logrados y conclusiones}

\subsection{Referente espacial: Localización y contextualización del área de estudio.}

El área de estudio se encuentra ubicada en la ciudad de Pereira, la cual está situada en un valle formado por la terminación de un ramal que se desprende de la cordillera central a los $40^{\circ} 49^{\prime}$ de latitud norte y $75^{\circ} 42^{\prime}$ de longitud oeste de Greenwich. Pereira limita al Norte con los municipios Risaraldenses de Balboa, La Virginia, Marsella, Dosquebradas y Santa Rosa de Cabal; al Oriente con el Departamento del Tolima; al Sur con los municipios de Circasia y Filandia

comercial), en los cuales se presentan mayores condiciones para la acumulación, esta situación tiende a privilegiar la inmigración hacia la conurbación Pereira-Dosquebradas.

${ }^{11}$ En 1989 Pereira y Manizales promediaban el $22 \%$ de Población Pobre por NBI, esta cifra asciende al 43\% cuando 
(Departamento del Quindío); al occidente con los municipios de Alcalá y Cartago (Departamento del Valle); posee una altitud de 1411 m.s.n.m.

$\mathrm{Su}$ extensión municipal es de 604 Kilómetros cuadrados; la ciudad está compuesta por 19 comunas; siendo las más pobladas el Centro, río Otún, Boston y Cuba. De igual manera, se han definido en el Plan de Ordenamiento Municipal para el área urbana y de expansión 15 Zonas de Planificación; entre ellas están la Zona Centro Metropolitano, Sector Oriental- Sector Otún Consota - Sector Sur, Sector Occidental Galicia, etc. (Véase Mapa 1). Entre otros aspectos, el territorio ocupado por asentamientos humanos se localiza en su mayoría en las colinas alargadas en sentido oriente occidente, separadas por depresiones profundas, que conducen en sus corredores ambientales los principales ríos que transitan la ciudad, el río Otún hacia el norte, el Consota hacia el sur y las quebradas La Dulcera, Boston, etc.

En particular, el área de estudio (borde urbano sur-oriental), se delimitó de manera detallada, por el sector comprendido entre el Barrio Hamburgo hasta el Barrio El Dorado. La superficie ocupada por estos asentamientos humanos es aproximadamente de 29,52 Ha., estimadas para el año 2000 por planeación Municipal. El barrio El Dorado se encuentra en la Comuna Consota (10); los barrios Poblado I y Hamburgo en la comuna El Poblado I (19); y en la Comuna San Nicolás (16) se localizan los asentamientos La Dulcera-Santa Librada y La Platanera (Véase Mapa 1). La zona de análisis se inscribe sobre el geocorredor de la cuenca del río Consota, que en su recorrido por esta zona urbana se caracteriza por su forma longitudinal y una configuración topográfica de laderas pendientes y pronunciadas; a su vez se demarca físicamente por la Avenida Las Américas (vía arteria principal) al norte; por el Río Consota, al sur; al oriente, por los barrios Hamburgo, La Dulcera y La Platanera; y al occidente, por el barrio El Dorado. (Véase Foto 1). 


\section{CATELIÊ GEOGRÁFICO ISSN: 1982-1956 REVISTA ELETRÓNICA

\section{Mapa 1. Comunas del municipio de Pereira. Localización del área de}

Investigación.

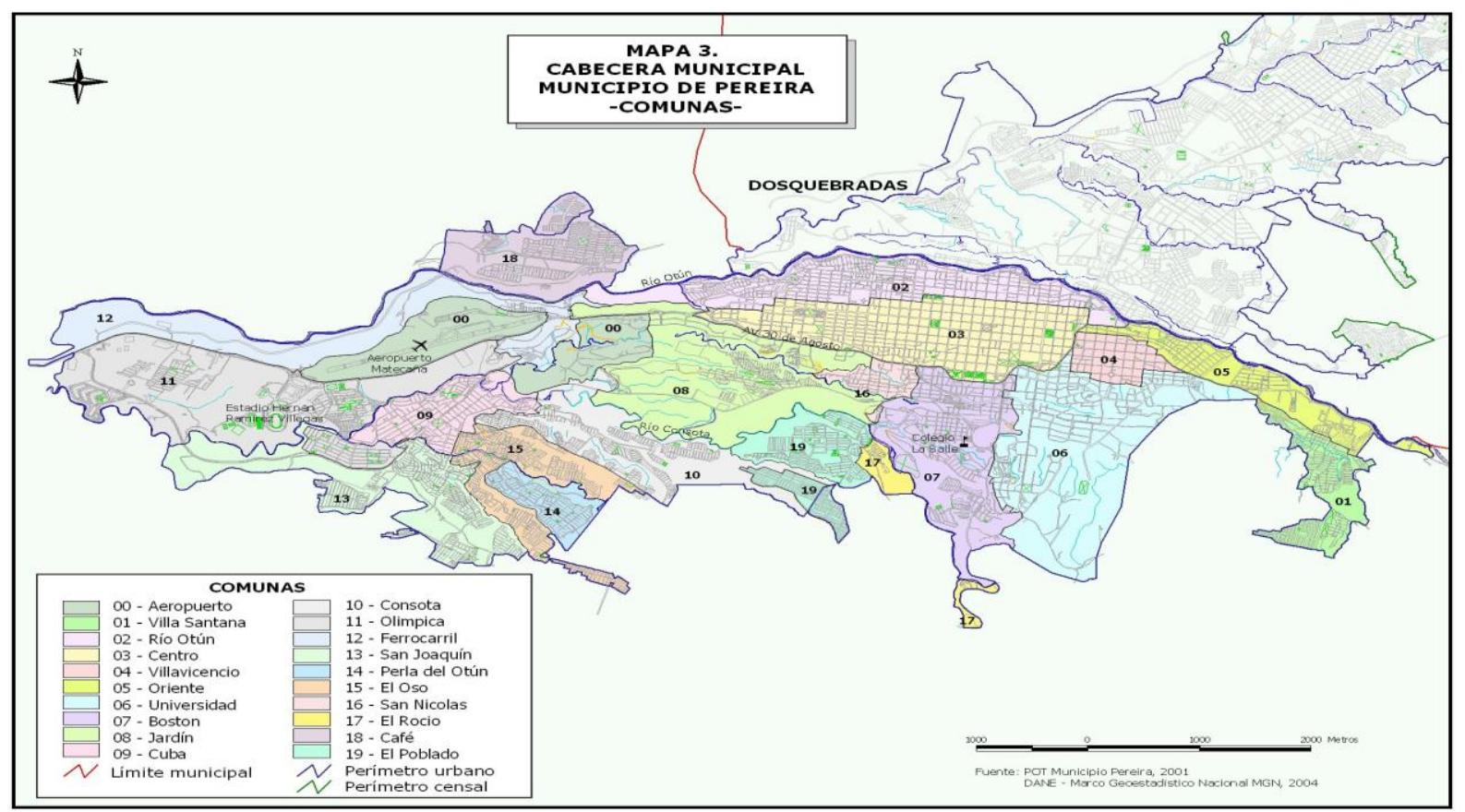

Fuente: DANE. Recuento de viviendas, hogares y unidades económicas. Pereira, 2004.

Foto 1. Fotografías aéreas del borde urbano sur-oriental de Pereira. (Barrios La Dulcera, La Platanera, El Poblado I, Hamburgo y El Dorado)
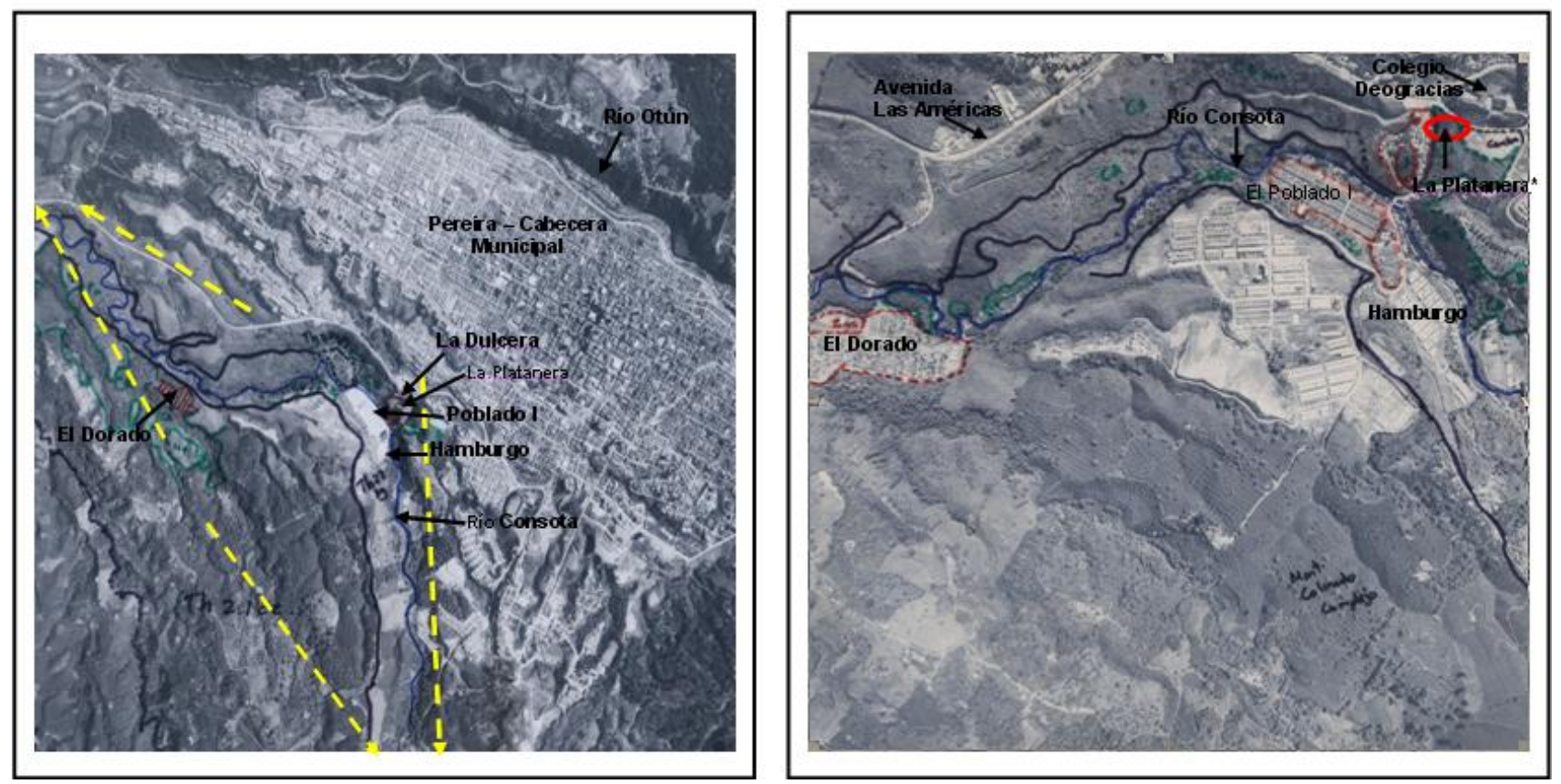

* En el año 1993 no se había conformado La Platanera; sin embargo se señala su ubicación actual.

Fuente: IGAC. Fotografías Aéreas C-2250, 1986; C-2515, 1993. 
Tabla 4. Análisis geográfico del proceso de territorialización y su relación con la segregación socio-espacial y los conflictos ambientales en el borde urbano sur oriental de Pereira (barrios La Dulcera, La Platanera, EI Poblado I, Hamburgo y El Dorado)

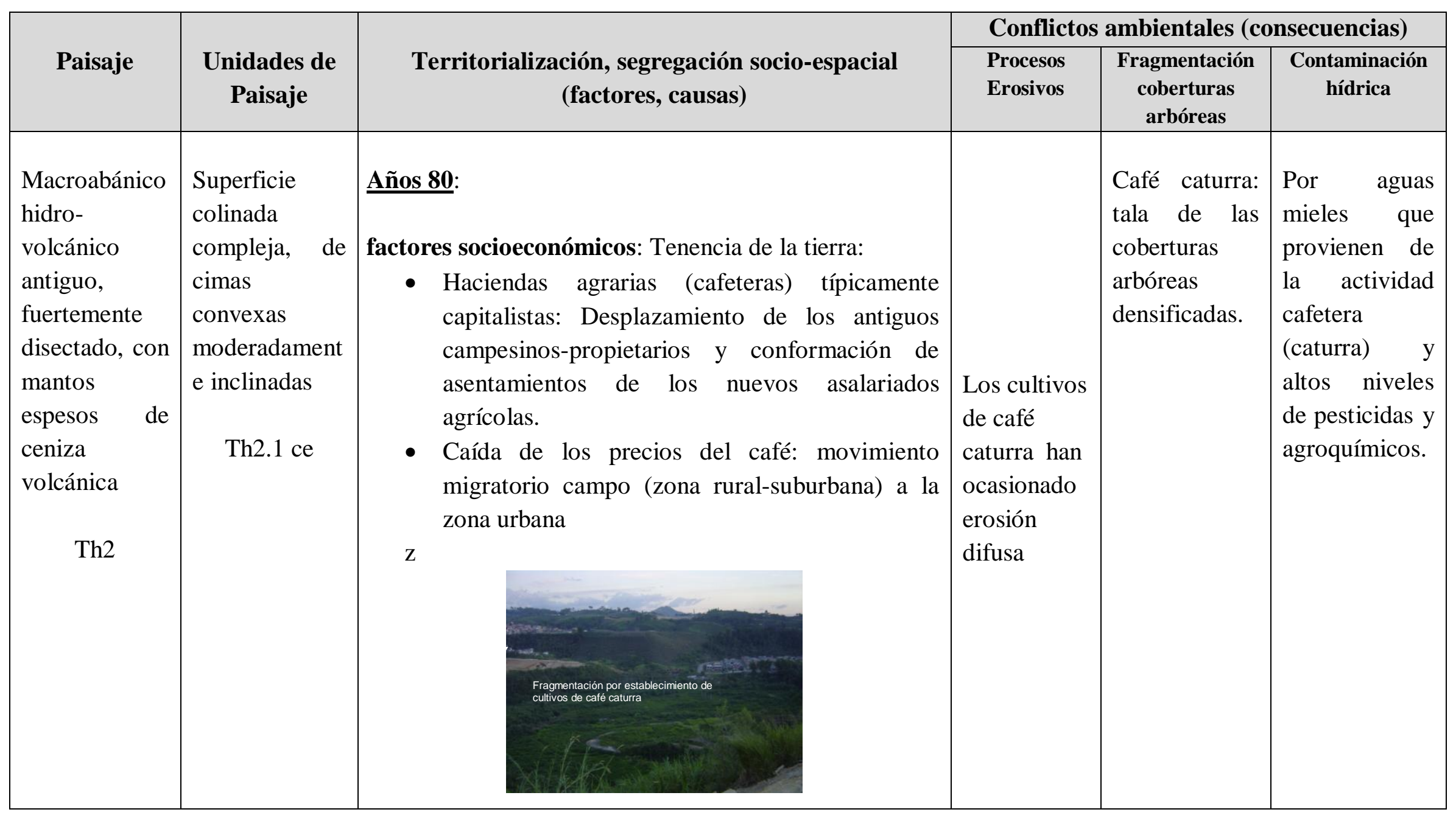




\section{REVISTA ELETRÔNICA}

Factor cultural:

- Sentido de lugar nostálgico y arraigado

\begin{tabular}{|c|c|c|c|c|c|}
\hline & & $\begin{array}{l}\text { Factor cultural: } \\
\text { - Sentido de lugar nostálgico y arraigado } \\
\text { Años 90: } \\
\text { factores socioeconómicos y políticos: } \\
\text { - Agudización de la crisis cafetera, } \\
\text { descentralización y disminución de funciones y } \\
\text { responsabilidades estatales en materia } \\
\text { socioeconómica } \\
\text { - Incremento del proceso migratorio campo- } \\
\text { ciudad } \\
\text { - Disminución del trabajo agrícola (cafetero) }\end{array}$ & & & \\
\hline $\begin{array}{l}\text { Ladera } \\
\text { denudativa de } \\
\text { valles en V, } \\
\text { en materiales } \\
\text { hidrovolcánic } \\
\text { os con } \\
\text { cobertura } \\
\text { discontinua de } \\
\text { ceniza } \\
\text { volcánica }\end{array}$ & $\begin{array}{l}\text { Laderas } \\
\text { empinadas a } \\
\text { fuertemente } \\
\text { empinadas con } \\
\text { erosión ligera } \\
\text { Th } 2.2 \mathrm{fg}\end{array}$ & $\begin{array}{l}\text { Años } 90 \\
\text { La Platanera: Invasión } \\
\text { factores socioeconómicos y políticos: } \\
\text { - Tenencia de la tierra: } \\
\text { - Desplazamiento forzado (de bajos recursos } \\
\quad \text { económicos. Sin posibilidad de incorporarse al } \\
\text { mercado "legal" de vivienda. } \\
\text { Factor cultural: } \\
\text { - Sentido de lugar social y nostálgico }\end{array}$ & $\begin{array}{l}\text { Por } \\
\text { extracción } \\
\text { de árboles, } \\
\text { trazado de } \\
\text { caminos, } \\
\text { construcció } \\
\text { n de } \\
\text { viviendas y } \\
\text { vías, } \\
\text { explotación } \\
\text { de canteras }\end{array}$ & $\begin{array}{l}\text { Extracción de } \\
\text { cobertura } \\
\text { forestal para } \\
\text { su utilización } \\
\text { como } \\
\text { combustible, } \\
\text { materia prima } \\
\text { para } \\
\text { construcción } \\
\text { de vivienda, } \\
\text { etc. }\end{array}$ & $\begin{array}{l}\text { Eliminación } \\
\text { (parcial) de } \\
\text { residuos } \\
\text { sólidos y } \\
\text { líquidos en } \\
\text { los drenajes y } \\
\text { el río Consota. } \\
\text { (La Platanera) }\end{array}$ \\
\hline
\end{tabular}




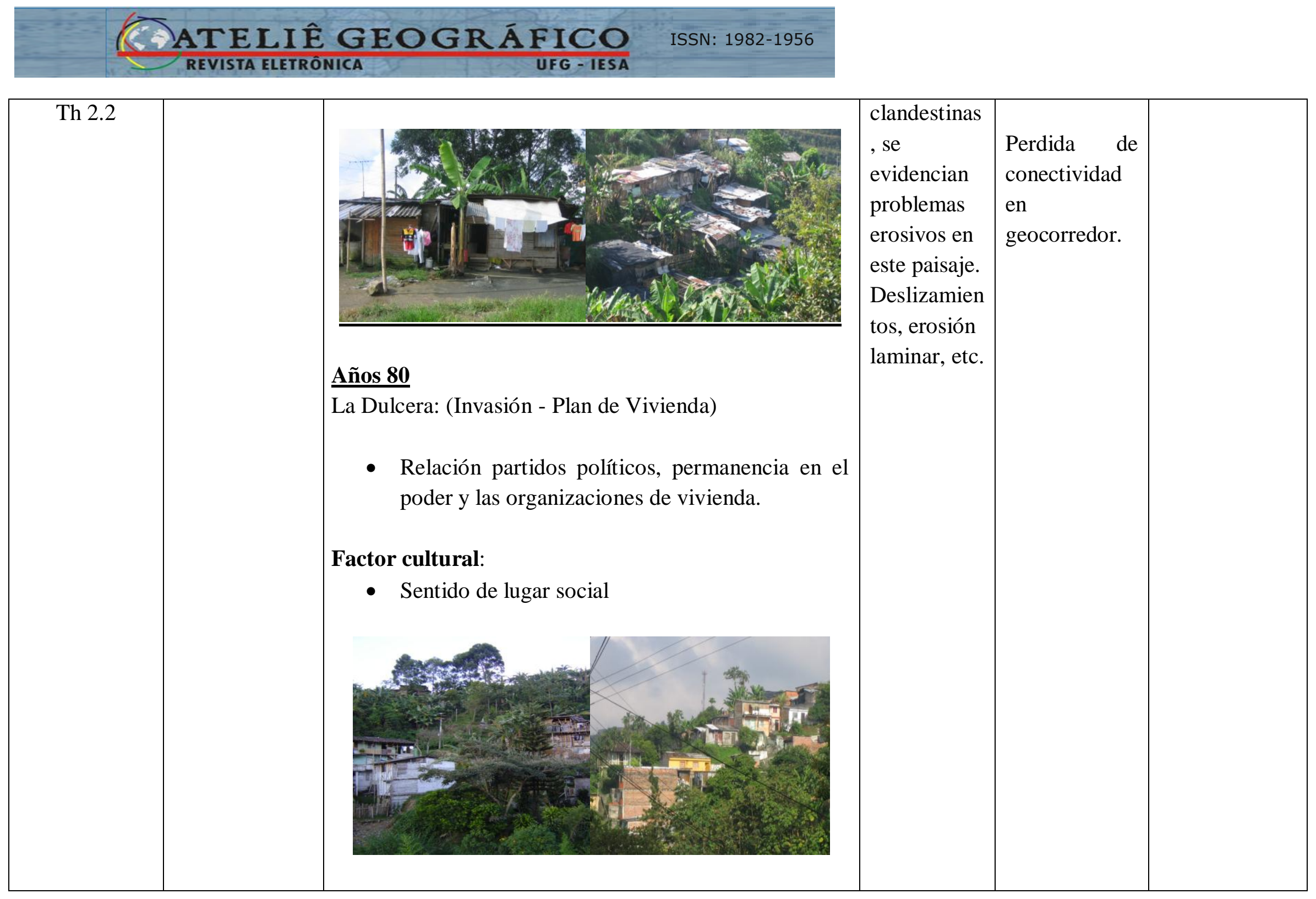




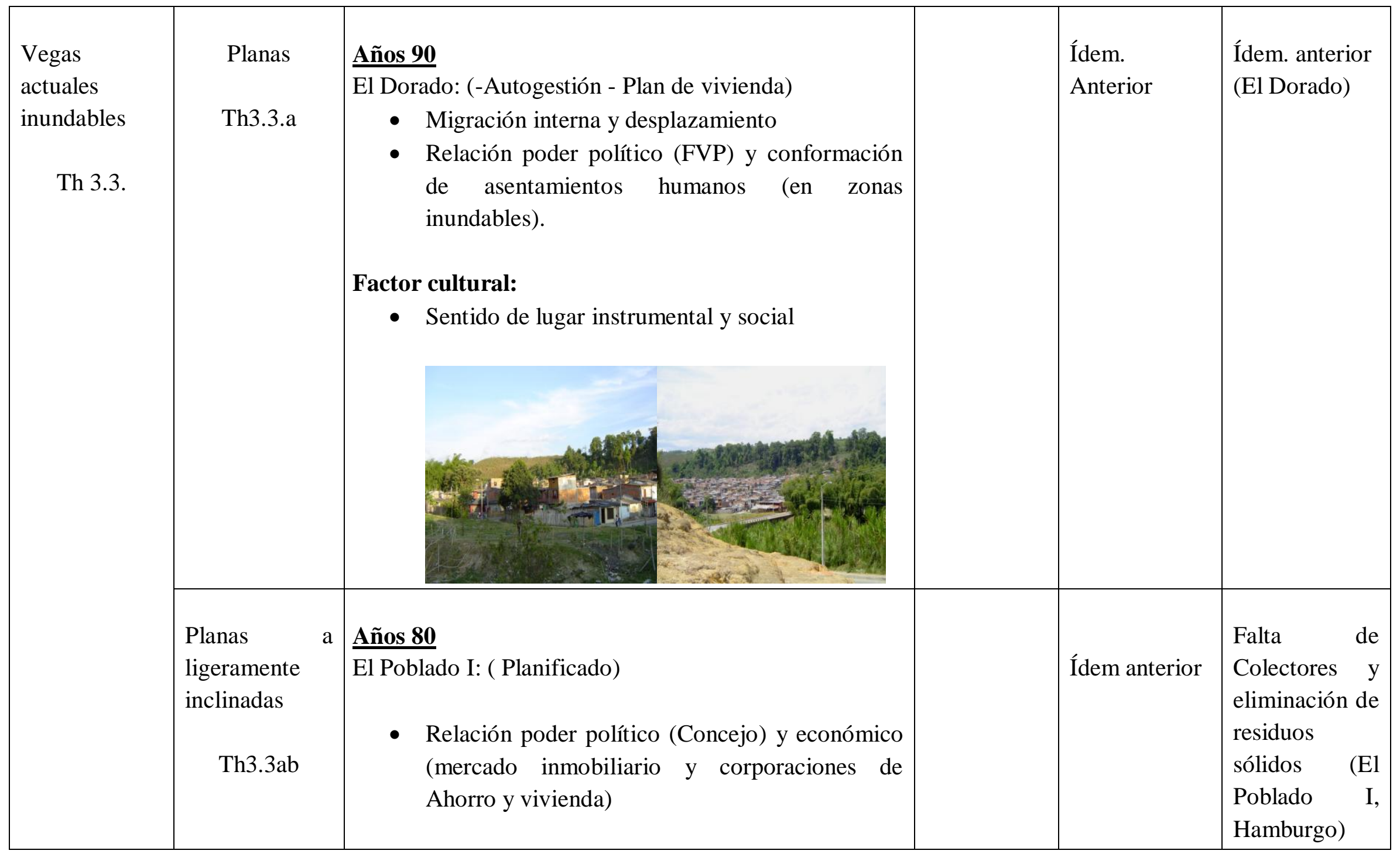




\section{SATELIÊ GEOGRÁFICO ISSN: 1982-1956}

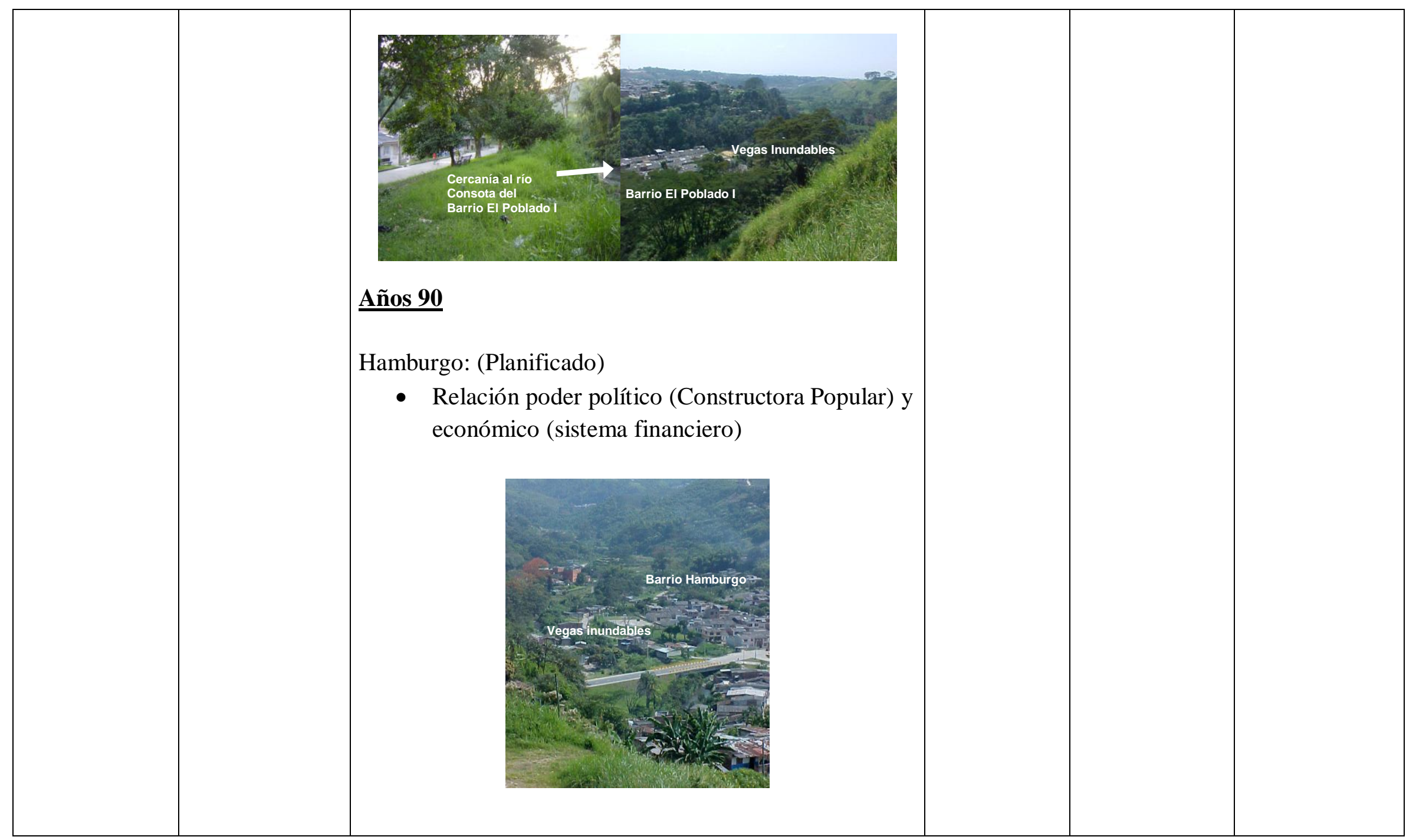

Fuente: Elaboración propia. 


\subsection{Territorialidades y segregación socio-espacial.}

Como exposición de las particularidades encontradas sobre la mutua e intrínseca relación entre los factores, variables y procesos socio-naturales, se enuncian los resultados en la tabla 4 titulada Análisis geográfico del proceso de territorialización y su relación con la segregación socio-espacial y los conflictos ambientales en el borde urbano sur oriental de Pereira (barrios La Dulcera, La Platanera, El Poblado I, Hamburgo y El Dorado).

En particular, y para dilucidar un caso paradigmático de este fenómeno se expone el área de "La Platanera", por ser un asentamiento humano constituido por procesos de invasión y en condición de segregación socio-espacial. En primer lugar, se ha podido estimar el origen de los inmigrantes, estableciendo que el asentamiento de La Platanera se formo inicialmente con una población 100\% Risaraldense (1996), pero actualmente el $64 \%$ de la población es Risaraldense y el $36 \%$ restante proviene de otros departamentos del país; así, el $75.8 \%$ de la población proviene predominantemente de Caldas, Choco y Valle. Considerando la variable del lugar de residencia cinco años atrás se reconoció de manera general que para el año 2000, el $80 \%$ de la población total de este asentamiento ya se encontraba en el departamento de Risaralda, aunque esto no signifique que todos ya habían llegado a la ciudad de Pereira.

De los análisis demográficos efectuados se comprobó que son muy dicientes las repercusiones que tienen las migraciones internas y el proceso de desplazamiento forzado de carácter nacional, regional y departamental, en la escala local (Pereira). Esto se evidencia en La Platanera, debido a que su población está constituida en una alta proporción por afrocolombianos (100 personas) provenientes del Choco (Bagado, Tado, Quibdó) y el área Noroccidental del departamento de Risaralda o Choco Biogeográfico (Municipio de Pueblo Rico-Corregimiento de Santa Cecilia y Mistrató) y Quinchía; asimismo confluyen en el asentamiento población desplazada de otros departamentos, principalmente de Caldas (Aguadas, Riosucio, Samana, Irra, Arma, etc), Valle (Guacarí, Versalles, Ulloa, etc.), pero también de Caquetá, Meta, Huila, Cauca, Antioquia y Santander. De esta forma, muchos pobladores del asentamiento son originarios de zonas con grandes tensiones territoriales por el conflicto armado; de la población consultada 140 personas eran mestizas y el resto del asentamiento (20, aprox.) estaba conformado por indígenas de la etnia Embera-Chami (Provenientes del Choco Biogeográfico, de Riosucio, etc).

Igualmente, se comprueba cómo el asentamiento de La Platanera se convierte en lugar de recepción de población desplazada, debido a factores sociales asociados a las características que reviste desde lo cultural como área de encuentro con sus "afines"; es por esta razón que el asentamiento posee un "sentido de lugar social", ya que representa el apoyo y encuentro en la ciudad de Pereira con los familiares, amigos o personas que como ellos han emigrado del mismo lugar de origen; siendo especial los casos de la población negra e indígena procedentes del Choco, la zona "del Choco Biogeográfico del departamento de Risaralda", y los resguardos de Riosucio-Caldas, 
Quinchía y del corregimiento de Santa Cecilia, Pueblo Rico- Risaralda. Esto confirma el supuesto teórico que la migración no es solamente un desplazamiento de población sino que en ella se configuran relaciones y dimensiones culturales, sociales, económicas y políticas.

En la misma dirección conceptual, se percibe "un sentido de lugar nostálgico" debido a que la zona de la Platanera presenta unas condiciones similares geográficamente a las que poseía el área de donde tuvieron que emigrar. Esta característica cultural es generalizada para la población negra que expone esta asociación con su lugar de origen (coberturas arbóreas, fuertes pendientes, humedad, la presencia del río, la posibilidad de encontrar materiales naturales para la construcción de sus viviendas, el desarrollo de los cultivos de "Plátano" como base alimenticia para su subsistencia); todos estos factores proporcionan la identidad con el lugar, y por ello también el asentamiento recibe el nombre de "La Platanera".

\section{Conclusiones}

Territorialización del borde urbano sur-oriental, años ochenta: Esta década fue un periodo coyuntural en la historia reciente del Municipio de Pereira, representando una inflexión y cambio en las condiciones socioeconómicas locales y regionales, especialmente, al convertirse en el inicio del declive de la economía cafetera. En este marco histórico, se gestó el proceso de territorialización de La Dulcera y El Poblado I, correspondiendo a dos tipologías diferentes en su origen y constitución, pero ambas subyacentes a las relaciones entre actores económicos y políticos. El primero, asociado a un proceso de invasión, y el segundo, resultado de los ejercicios de planificación estatal de la "Vivienda popular". De manera particular, la expresión de territorialidad que tuvo su inicio en un proceso de invasión (La Dulcera), refrenda como fue permeada por los grupos de poder, generándose una relación triangular entre las organizaciones de vivienda, la administración pública, los partidos políticos, y su deseo de permanencia en el poder.

Simultáneamente, se puede afirmar de manera concluyente que la transformación y degradación ambiental del borde sur-oriental (fragmentación de la cobertura arbórea existente, etc.) es determinado, en gran proporción, por el proceso de urbanización y territorialización reciente de asentamientos humanos caracterizados por la segregación socio-espacial; no obstante, sin extender culpabilidad o señalar de facto a la población que conforma dichos asentamientos, muy por el contrario, en la perspectiva de reconocer las verdaderas causalidades, se limita la responsabilidad de los desplazados y población en línea de pobreza, que está luchando diariamente por su supervivencia, de tal suerte que los recursos naturales y los servicios que estos prestan desde un enfoque ecológico, no son el centro de la preocupación de esta población. Así, las consecuencias ambientales de la territorialización del borde o periferia se dilucidan a partir de los factores expuestos con anterioridad, como son: La relación entre los grupos de poder económico y político que trazan las directrices del uso del suelo y manejan el 
mercado de la construcción de vivienda, y asimismo, la invisibilidad de una política pública de vivienda.

\section{Gráfico 2. Territorialidades en Pugna. Años Ochenta.}

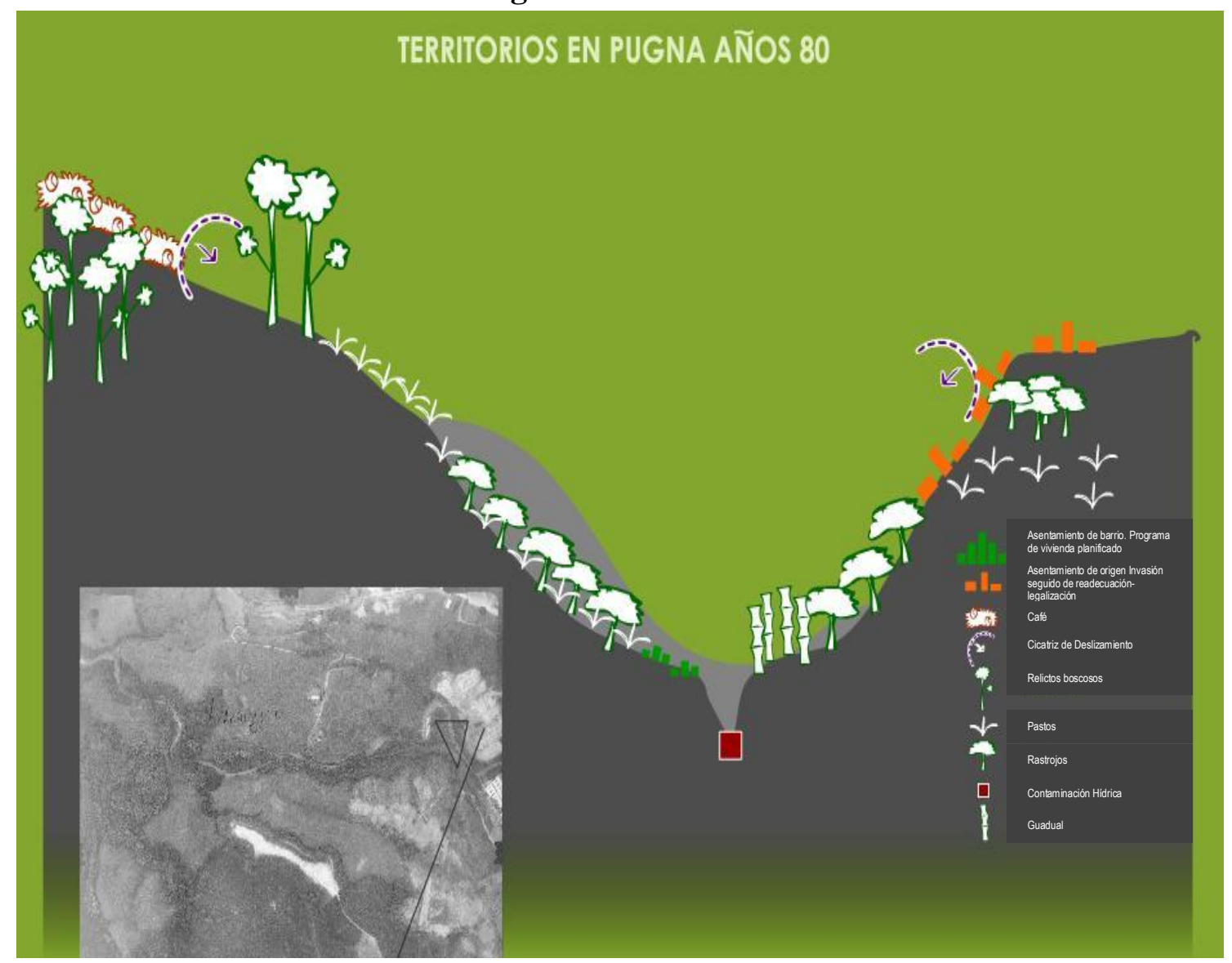

Fuente: Jorge Andrés Rivera Pabón

Territorialización del borde urbano sur-oriental, años noventa: Se considera la década de los noventa y primeros años de este nuevo milenio como tiempos de la internacionalización de la economía y sus efectos en el ámbito local. Además, se inscribe en la discusión las consecuencias de las reformas del Estado, su papel en el desarrollo de la política de vivienda, entre otras variables políticas, económicas y sociales. En especial, para Pereira esta década generó unas altas tasas de desempleo y pobreza que son inocultables, correlacionándose con los efectos de la crisis cafetera, la migración campesina y el recrudecimiento de la violencia. De acuerdo con el Observatorio del Programa Presidencial de Derechos Humanos y el Informe regional de Desarrollo Humano (2004, p. 18), en el 2000 se triplicó la actividad armada en el eje cafetero frente a los niveles registrados durante la década del noventa ${ }^{12}$. Este fenómeno

\footnotetext{
${ }^{12}$ Como señala esta fuente, en ese mismo año se registraron un total de 31 contactos armados entre la fuerza pública y las guerrillas (frente a 5 en promedio, en la primera mitad de los noventa). Citado por: PNUD. Informe regional de Desarrollo Humano. Un pacto por la región. 2004. p. 18.
} 
se articula con la conformación de los asentamientos humanos del Dorado y La Platanera, ya que el desplazamiento es uno de los factores impulsores del origen y crecimiento permanente que han tenido dichos asentamientos.

\section{Gráfico 3. Territorialidades en Pugna. Años Noventa.}

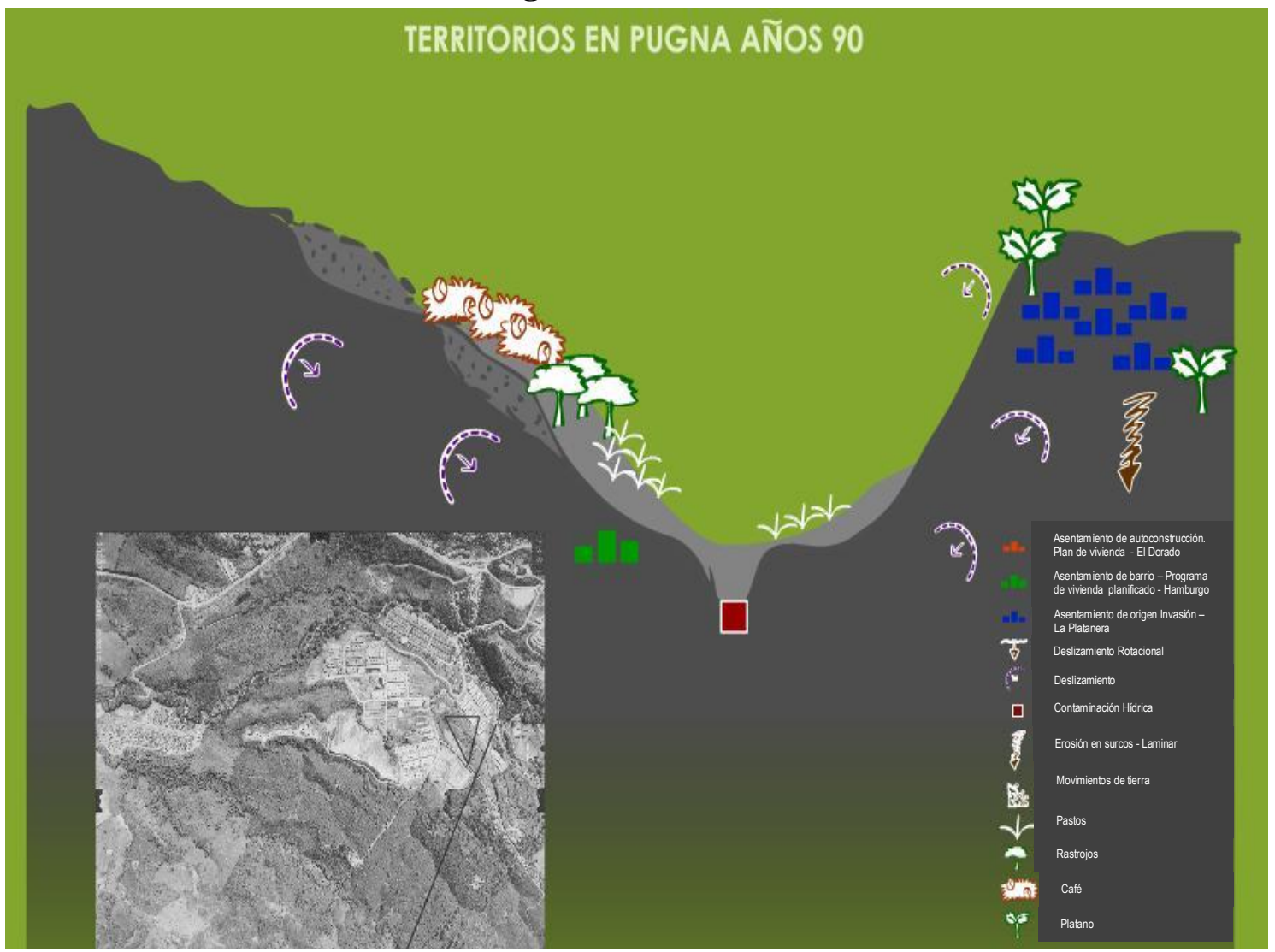

Fuente: Jorge Andrés Rivera Pabón

Además, es muy importante para el reconocimiento del por qué de estos asentamientos de Invasión, la suspensión en la década de los noventa de la función social y económica que cumplía el Estado a través del Instituto de Crédito Territorial, el Fondo de Vivienda Popular y finalmente del INURBE. A pesar del aumento del proceso de migración durante esta década ${ }^{13}$ y del incremento en la demanda de vivienda, el Estado en cumplimiento de las exigencias internacionales de reducción del aparato burocrático y de reestructuración administrativa (para ser competitivos) clausuro una labor que es propia de su naturaleza pública y razón de su existencia, la búsqueda de soluciones para la prestación de los servicios y condiciones básicas de vida de sus ciudadanos. Como respuesta se adjudico esta función al sector financiero (cerrando

\footnotetext{
${ }^{13}$ De manera particular, los datos de Pereira en los noventa confirmaron que ésta seguía siendo una ciudad receptora de importantes flujos migratorios. Según el censo de 1993 una de cada dos personas nació fuera de esta ciudad (10\% en otros municipios de Risaralda y $40 \%$ en municipios de otros departamentos). Por supuesto, esta información no cubrió la masiva inmigración posterior a 1993 que en el país se habla que alcanzó alrededor de un millón de personas, huyendo de manera forzosa de la violencia y buscando refugio en los barrios populares de las ciudades. Citado con base en: ARANGO, 2000. Op., cit. P. 45.
} 
también las Corporaciones de Ahorro y Vivienda que prestaron créditos por más de treinta años, tal es el caso de la Urbanización Hamburgo), coligado al sector de la población con mayor poder económico, político y sobre la tierra. De esta forma se afianzó como política de urbanización de la ciudad, la valoración estratégica de otras tierras de borde y periferias urbanas, de propiedad de la población de mayor poder (ejemplo Cerritos, periurbanización "vía Armenia").

Este y otros ejemplos, expresan las múltiples contradicciones del mercado capitalista de la tierra y la construcción de vivienda, sintomático de la década de los noventa y agudizado en estos primeros años del nuevo milenio. Sin lugar a dudas, la existencia de asentamientos humanos como La Platanera, El Dorado y muchos de este tipo por venir, son el resultado de la apatía del Estado por reconocer el rol fundamental que debe cumplir en la búsqueda de ofrecer soluciones a los problemas más neurálgicos del país (la lucha por el territorio-tenencia de la tierra, la vivienda, la educación, etc) que son la causa de estas concentraciones de población que intentan desarrollar y proseguir su vida en un ámbito espacial que les permita la supervivencia, lejos de los enfrentamientos de los grupos armados, la presión de la fuerza pública para que no vuelvan a sus tierras ${ }^{14}$, entre otros factores. Igualmente, el no existir la mínima posibilidad para esta población desplazada de bajos recursos de insertarse dentro del "mercado legal de vivienda" hace que estemos abocados a la consolidación y crecimiento constante de este tipo de asentamientos humanos.

\section{Referencias}

ARANGO Oscar. Pereira Años 80. Funderalda, 1989.

ARANGO Oscar. Pereira Años 90.UTP-GTZ, 2000.

CORAGGIO, José Luis. Sobre la Espacialidad social y el concepto de región. 1979.

DANE. Censos nacionales de población. 1870-1993.

DANE-Alcaldía de Pereira. Encuesta Continua de Hogares. Etapa 01 de 2003.

ESTEBANEZ A. José. Geografía Urbana-1. La dimensión espacial en el estudio de la ciudad. Madrid, 1994.

GARCIA, Ballesteros, Aurora. Geografía Urbana. La ciudad, objeto de estudio disciplinar. 1995.

GOTTDIENER, M. The Social Production of the Space. University Texas Press, 1985

HARVEY, D. The Condition of Postmodernity. Oxford: Basil Backwell, 1989

LOBATO CORRÊA, R. O espaço urbano. Sao Paulo: Ática, 1990.

MOLANO B, Joaquín. Arqueología del paisaje. Anotaciones sobre Planeación. En: Espacio y Naturaleza, No. 44. Medellín. Universidad Nacional. 1994.

\footnotetext{
14 Afirmación realizada por varios desplazados de La Platanera, en su mayoría de Riosucio y Santa Cecilia, corregimiento de Pueblo Rico, advirtiendo que si regresaban nuevamente serian enjuiciados y encarcelados como colaboradores de la guerrilla. (Historias de vida).
} 
NACIONES UNIDAS. The determinants and consecuences of population trends. Vol 1, Capítulo VI, 1993.

PEET Richard. Modern Geographical Thought. Blackwell Publishers. Oxford, 1998.

PNUD. Informe regional de Desarrollo Humano. Un pacto por la región. 2004

RED DE SOLIDARIDAD SOCIAL-UNIDAD TERRITORIAL RISARALDA. El desplazamiento en el departamento de Risaralda. 2003

RODRIGUES, S. Paulo. Contradicciones de la producción de la vivienda en la ciudad de rio grande, Brasil. En: Revista electrónica de geografía y ciencias sociales Scipta Nova. $\mathrm{N}^{0} 45$ (3). 1999

SANCHEZ, Joan- Eugeni. Espacio, economía y sociedad. Siglo XXI de España Ed. Madrid, 1991.

SANTOS, Milton. Metamorfosis del espacio habitado. Iokos-tau. 1996.

SOJA, E. Postmodern Geographies. The Reassertion of Space in Critical Social Theory, Verso Londres y Nueva York, 1989

VILLOTA, Hugo. Análisis de los atributos del paisaje en la zonificación ecológica. IGAC- CIAF. 1999.

VILLOTA Hugo. Geomorfología aplicada a levantamientos edafológicos y zonificación física de las tierras. IGAC. Bogotá, 1991

Recebido para publicação em setembro de 2008

Aprovado para publicação em dezembro de 2008 